\title{
A Rapid Parametric Modeling Method of SWATH Based on Siemens NX Extended Development
}

\author{
Qu Yang ${ }^{1}$, Guan Guan ${ }^{1,2, *}$, Yan Lin ${ }^{1,2}$ and Lei Wang ${ }^{1}$ \\ ${ }^{1}$ Ship CAD Engineering Center, Dalian University of Technology, Dalian 116024, China \\ ${ }^{2}$ State Key Laboratory of Structural Analysis for Industrial Equipment, Dalian University of Technology, Dalian 116024, China \\ ${ }^{*}$ Corresponding author
}

\begin{abstract}
A rapid parametric modeling method capable to automatically build and modify the form of SWATH based on Siemens NX extended development is described, aiming at solving the problem of long time consuming and low utilization of the traditional SWATH modeling method. The underwater hull and strut are parameterized based on the analysis of SWATH profile. The modeling strategy is driven by the extended development program with the use of UG/OPEN API tool provided by Siemens NX. The validity of the method is proven in the case of a $2.7 \mathrm{~m}$ SWATH experimental model. The method can provide a flexible model for subsequent design and optimization.
\end{abstract}

Keywords-SWATH; siemens NX extended development; parametric modeling

\section{INTRODUCTION}

Small Waterplane Area Twin Hull (SWATH) were originated from Europe in 19th century. By the 1970s, with the application of hydrodynamics in ship design, the concept of small waterplane area was introduced into semi-submerged catamaran. Hence, a SWATH combines the best of two areas, such as optimal seakeeping performance and high speeds ${ }^{[1]}$. However, the design of SWATH is challenging as the lack of reference ships and statistical data ${ }^{[2]}$. In addition, the test technique and measuring method for SWATH model are more complex than the conventional ship resulting in costing lots of time and material sources to carry out series of model tests. Consequently, numerical simulation method based on numerical model is widely applied for ship design to shorten the design cycle. The traditional numerical modeling method for SWATH is to divide the parameters into main dimension parameters and profile parameters. Main dimension parameters are used to decide the size, while profile parameters are used to control the shape. The profile of the underwater hulls and struts are obtained by matching and fitting the circular, parabola, or arbitrary curves ${ }^{[3]}$. As a result, it is time consuming and inconvenient to modify the models which will be used in design process by conventional modeling method. In order to solve the above problem, a parametric modeling method is proposed to obtain the numerical model quickly by constraining the relationship between parameters.

Currently, SWATH parametric modeling methods are scarce. Cheng et al. analyzed SWATH shipform characteristics, generated the sectional area curve and the pillar thickness distribution curve based on sections, and implemented 3D modeling in AUTOCAD. ${ }^{[4]}$ Subramanian et al. calculated the parameters of SWATH based on the Chebyshev polynomials, and SWATH shipform was expressed by double 5-times Bspline ${ }^{[5]}$. Wang et al. realized parametric modeling of the subbody and pillar profiles by using NURBS ${ }^{[3]}$. Brizzolara et al. chose the 3 largest diameter positions of the submarine as parameters and fitted SWATH ship lines by the $8^{\text {th }}$ order polynomial, when they were studying the hydrodynamic characteristics of SWATH ${ }^{[6,7]}$. However, the models generated by these methods are difficult to be integrated with other optimization and computing software and these methods can not provide the original model quickly for subsequent calculation and optimization.

According to the characteristics of SWATH, this paper combines the UG/OPEN API technology in Siemens NX software with the parametric SWATH ship model to realize SWATH parametric rapid modeling.

\section{SiEMENS NX AND SECONDARY DEVELOPMENT TOOLS}

Siemens NX (NX) is a 3D CAD software being widely used in automotive, aerospace and other mechanical design industries ${ }^{[8]}$. It provides design environment and parametric drive modeling mechanism based on process, and has powerful feature modeling capabilities. An important factor in parametric modeling in NX is the expression. By changing the dimensions of the expression, the model will achieve the corresponding changes. The change in model size is essentially achieved by changing the size expression of the constraint model. It is very suitable for such special type of ship as SWATH.

Siemens NX provides secondary development tools UG/OPEN API, you can easily operate NX graphics terminals and data. It supports $\mathrm{C} / \mathrm{C}++$ language, you can use powerful $\mathrm{VC}++$ integrated environment to compile. According to the different operating environment, UG/OPEN API program can be divided into two modes, external program mode and internal program mode. The operation in External program mode is irrelevant to the environment of $\mathrm{NX}$, the program can be run out of $\mathrm{UG}^{[9]}$. The program in internal mode only can be run in $\mathrm{NX}$, the application program can be compiled to dynamic link library file by VC, and the dynamic link library file can be loaded when UG is being started up, and called through the user menu.

As a part of the process of ship design and optimization, SWATH parametric modeling should avoid reliance on the NX environment and allow the parameterization program to run independently. Therefore, the development of the external 
program mode of UG/OPEN API to SWATH parameterization modeling is more applicable.

\section{SWATH PARAMETRIC MATHEMATICAL MODEL}

SWATH is composed of three parts: underwater submersibles, water platform and pillars. In ship design, the submersibles and pillars below the waterline are directly related to each performance ${ }^{[10]}$. Therefore, the focus should be on the design of the submersibles and pillars below the waterline. In general, SWATH is completely symmetrical, so only one of its submarines and pillars are taken to study in this paper.

\section{A. Submersible Parametric Mathematical Model}

For SWATH, considering both the performances and processing technology, the shipform design should try to make the shape of the submersible regular ${ }^{[7]}$. Therefore, this paper is aimed at the submersible with circular sections. In NX, as long as the parametric expression of the generatrix of submersible is obtained, the submersible model can be established easily by rotation.

To express the generatrix of submersible, introduce two dimensionless numbers:

$$
\left\{\begin{array}{l}
x=\frac{X}{L} \\
y=\frac{Y}{D}
\end{array}\right.
$$

Where, $X$ is the length direction coordinate of the submersible, $\mathrm{m} ; L_{h}$ is the total length of the submersible, m; $Y$ is the vertical coordinate of the generatrix of submersible, $\mathrm{m}$; $D$ is the maximum diameter of submersible, $\mathrm{m}$. (2):

The generatrix of submersible can be expressed as formula

$$
y^{2}(x)=\sum_{k=1}^{6} a_{k} x^{k}
$$

Where, $a_{k}(\mathrm{k}=1,2, \ldots, 6)$ are 6 parameters which are determined by the maximum diameter location of the submersible $\left(X_{h m}\right)$, bow radius $\left(R_{\text {bow }}\right)$, and stern radius $\left(R_{\text {stern }}\right)$,with the drainage volume $(V)$,total length $\left(L_{h}\right)$, and the maximum diameter ( $D$ ) of the submersible given. As shown in Figure 1, according to the mathematical characteristics of the curve, and the ship's physical characteristics, the relevant parameters of the submersible should meet the following constraints:

$$
\left\{\begin{array}{c}
y^{\prime}\left(x_{m}\right)=0 \\
y(1)=0 \\
y\left(x_{m}\right)=\frac{1}{2} \\
\int_{0}^{1} y^{2}(x) d x=\frac{c_{p}}{4} \\
\frac{\sqrt[3]{2}}{\sqrt{1+y^{\prime^{\prime}}(0)}}=r_{\text {bow }} \\
y^{\prime^{\prime}(0)} \\
\frac{\sqrt[3]{2}}{y^{1+y^{\prime}(1)}(1)}=r_{\text {bow }}
\end{array}\right.
$$

Where, $C p$ is the longitudinal rhombus coefficient of the submersible, $C_{p}=\frac{4 \nabla}{\pi D^{2} L}, \nabla$ is the drainage volume of the submersible; $r_{\text {bow }}$ is bow radius of curvature of the generatrix of submersible, $r_{\text {bow }}=R_{\text {bow }} L / D^{2} ; r_{\text {stern }}$ is stern radius of curvature of the generatrix of submersible, $r_{\text {stern }}=$ $R_{\text {stern }} L / D^{2}$.

Combined equation (2) with equation (3), $a_{k}$ can be solved, the generatrix expression of submersible can be obtained.

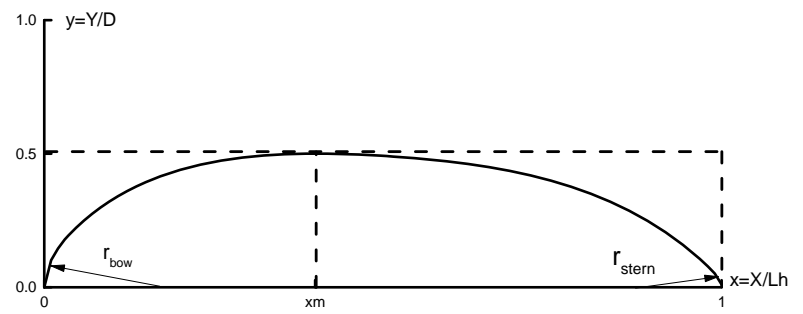

FIGURE I. SCHEMATIC DIAGRAM OF PARAMETRIC EXPRESSION OF GENERATRIX EXPRESSION OF SUBMERSIBLE

\section{B. The Parametric Mathematical Model of Pillar}

Pillar is a thin streamlined cylinder, which combine the underwater submersible and water platform into one. According to the sectional shape, the pillar can be divided into straight and curved surface type. The shape of the waterline of the straight surface type is the same with each height, the shape of section is two straight lines. The shape of the waterline of the curved surface type is different with each height, the shape of section is two curves. In this paper, the straight-type pillar is used. The parameterized formula of the waterline is shown as formula (4) ${ }^{[5]}$.

$$
\mathrm{Y}_{s}\left(X_{S}\right)=\frac{t_{s}}{2 L_{s}}-\frac{2 t_{s}}{L_{s}{ }^{3}} X_{s}^{2}
$$

Where, $Y_{S}$ is the half width of the waterline, $\mathrm{m} ; X_{s}$ is the longitudinal position of the waterline, $\mathrm{m}$; $t_{s}$ is the maximum pillar thickness, $\mathrm{m} ; L_{s}$ is the pillar length, $\mathrm{m}$. The origin of the coordinate is the midpoint of the longitudinal symmetry line in the waterline of the pillar, as shown in figure 2 . 


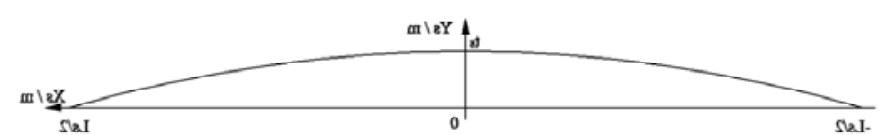

FIGURE II. THE HALF WATERLINE OF THE PILLAR SCHEMATIC

\section{SWATH PARAMETERIZATION BASED ON UG / OPEN API}

This paper makes use of the UG/OPEN API interface provided by NX for secondary development. It can update the parameterized geometric model according to the input SWATH parameters. The program runs independently of the NX environment. It can automatically generate model files which are compatible with numerical simulation software and can be integrated with third-party optimization platforms. The basic idea includes two parts:

(1) Create a model driven by the related parameters of SWATH submersible and pillar, including basic geometry and topological relationships of submersible and pillar. The parameters are associated with expressions. Save this model as a template file.

(2) According to the given parameters, through the second development, edit expression parameters value of expression in the template file, and then drive the system to generate a new model.

According to the above, adopt UG/OPEN API external mode and $\mathrm{VC}++$ to carry on parametric modeling as shown in figure 3.

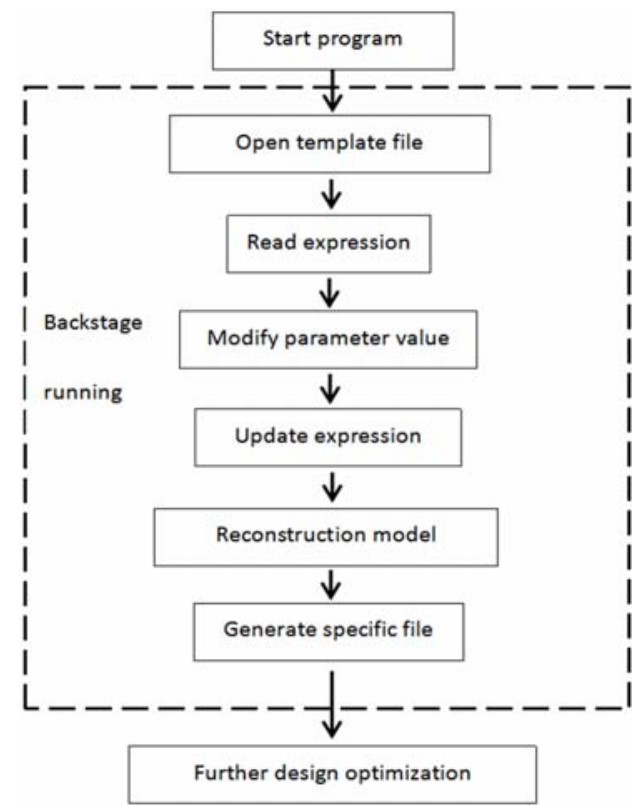

FIGURE III. THE PARAMETRIC MODELING BASED ON UG / OPEN API SECONDARY DEVELOPMENT

\section{APPLICATION EXAMPLE}

Take a $2.7 \mathrm{~m}$ SWATH model in David W. Taylor ship R \& $\mathrm{D}$ center in the United States for towing tests as example to explain the parameterized rapid modeling method specific process.

\section{A. $2.7 m$ SWATH Model Parametric Rapid Modeling}

Firstly, create a template file, and build model and expressions in NX. The basic information of the ship model is shown in Table I.

BASIC MODEL INFORMATION OF 2.7M SWATH

\begin{tabular}{|c|c|}
\hline Submersible length $L_{\mathrm{h}}(\mathrm{m})$ & 2.7 \\
\hline Largest diameter of submersible $D(\mathrm{~m})$ & 0.4 \\
\hline Drainage volume of submersible $\nabla\left(\mathrm{m}^{3}\right)$ & 0.659 \\
\hline Largest diameter position of submersible $x_{\mathrm{m}} \mathrm{x}_{\mathrm{m}}$ & 0.36 \\
\hline Bow radius $r_{\text {bow }}$ & 0.5 \\
\hline Stern radius $r_{\text {stern }}$ & 0.1 \\
\hline Pillar length $L_{\mathrm{s}}(\mathrm{m})$ & 1 \\
\hline Pillar largest thickness $t_{\text {smax }}(\mathrm{m})$ & 0.1 \\
\hline
\end{tabular}

Secondly, according to the parameterized formula, the six parameters used to express the generatrix of the submersible are shown in Table II. Only the underwater part of the model is considered, so only the underwater part is established when modeling, and the parametric model as shown in Figure. 4.

\section{PARAMETERS USED TO EXPRESS THE GENERATRIX OF THE} SUBMERSIBLE

\begin{tabular}{|c|c||c|c|}
\hline $\mathrm{a}_{1}$ & 1 & $\mathrm{a}_{4}$ & 50.89607 \\
\hline $\mathrm{a}_{2}$ & 3.3212 & $\mathrm{a}_{5}$ & -45.8407 \\
\hline $\mathrm{a}_{3}$ & -24.6788 & $\mathrm{a}_{6}$ & 15.3022 \\
\hline
\end{tabular}

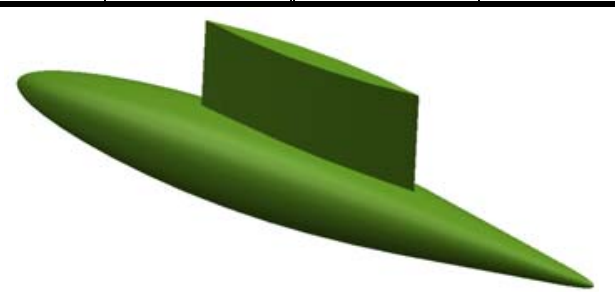

FIGURE IV . A 2.7M SWATH PARAMETRIC MODEL

\section{B. $2.7 m$ SWATH Parametric Model Rapid Transformation}

Based on the model above (original model), the model is transformed quickly by changing the maximum diameter location of the submersible and keeping other parameters unchanged. The program can automatically identify the parametric file which is modified, the NX software is opened in the background, and the new model will be generated quickly after the expression is modified. As shown in Table III, the maximum diameter location of the submersible of Model 1 is moved to the bow direction by 0.4 from the original model, and the maximum diameter location of the submersible of Model 24 is gradually moved to the stern direction by 0.4 from the original model. After the program is calculated in the background, the generatrix parameters of the submersible of the transformation model are obtained, the model is quickly generated. Table III shows the basic parameters comparison between the transformation model and original model. Table IV shows the comparison of the generatrix parameters of the submersible between the transformation model and original model. 
THE BASIC PARAMETERS COMPARISON BETWEEN THE TRANSFORMATION MODEL AND ORIGINAL MODEL

\begin{tabular}{|c|c|c|c|c|c|}
\hline $\begin{array}{c}\text { SWATH Main } \\
\text { Parameter }\end{array}$ & $\begin{array}{c}\text { Original } \\
\text { Model }\end{array}$ & $\begin{array}{c}\text { Model } \\
\mathbf{1}\end{array}$ & $\begin{array}{c}\text { Model } \\
\mathbf{2}\end{array}$ & $\begin{array}{c}\text { Model } \\
\mathbf{3}\end{array}$ & $\begin{array}{c}\text { Model } \\
\mathbf{4}\end{array}$ \\
\hline$L_{\mathrm{h}}(\mathrm{m})$ & 2.7 & 2.7 & 2.7 & 2.7 & 2.7 \\
\hline$D(\mathrm{~m})$ & 0.4 & 0.4 & 0.4 & 0.4 & 0.4 \\
\hline$\nabla\left(\mathrm{m}^{3}\right)$ & 0.659 & 0.659 & 0.659 & 0.659 & 0.659 \\
\hline$x_{\mathrm{m}}$ & 0.4 & 0.36 & 0.44 & 0.48 & 0.52 \\
\hline$r_{\text {bow }}$ & 0.5 & 0.5 & 0.5 & 0.5 & 0.5 \\
\hline$r_{\text {stern }}$ & 0.1 & 0.01 & 0.01 & 0.01 & 0.01 \\
\hline$L_{\mathrm{s}}(\mathrm{m})$ & 1 & 1 & 1 & 1 & 1 \\
\hline$t_{\mathrm{smax}}(\mathrm{m})$ & 0.1 & 0.1 & 0.1 & 0.1 & 0.1 \\
\hline
\end{tabular}

THE COMPARISON OF THE GENERATRIX PARAMETERS OF THE SUBMERSIBLE BETWEEN THE TRANSFORMATION MODEL AND ORIGINAL MODEL

\begin{tabular}{|c|c|c|c|c|c|}
\hline $\begin{array}{c}\text { Submersi } \\
\text { ble } \\
\text { Paramet } \\
\text { ers }\end{array}$ & $\begin{array}{c}\text { Original } \\
\text { Model }\end{array}$ & $\begin{array}{c}\text { Model } \\
\mathbf{1}\end{array}$ & $\begin{array}{c}\text { Model } \\
\mathbf{2}\end{array}$ & $\begin{array}{c}\text { Model } \\
\mathbf{3}\end{array}$ & $\begin{array}{c}\text { Model } \\
\mathbf{4}\end{array}$ \\
\hline $\mathrm{a}_{1}$ & 1 & 1 & 1 & 1 & 1 \\
\hline $\mathrm{a}_{2}$ & -0.47535 & 3.3212 & 1.21423 & 0.4447 & -0.1392 \\
\hline $\mathrm{a}_{3}$ & 0.6015 & -24.6788 & -12.6831 & - & -6.9197 \\
\hline $\mathrm{a}_{4}$ & -8.5647 & 50.89607 & 26.982 & $\begin{array}{c}20.564 \\
5\end{array}$ & 17.6698 \\
\hline $\mathrm{a}_{5}$ & 12.4262 & -45.8407 & -25.5716 & $\begin{array}{c}20.948 \\
6\end{array}$ & -19.8102 \\
\hline $\mathrm{a}_{6}$ & -4.9877 & 15.3022 & 9.0585 & 7.8591 & 7.87048 \\
\hline
\end{tabular}

Figure 5 shows the comparison of the generatrix of the submersible between the transformation model and original model. Figure 6 shows the comparison of the submersible between model 3 and the original model in NX.

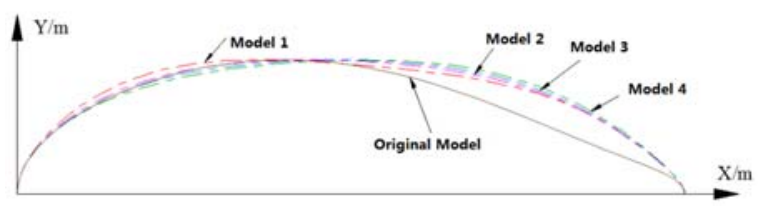

FIGURE V. COMPARISON OF THE GENERATRIX OF THE SUBMERSIBLE BETWEEN THE TRANSFORMATION MODEL AND ORIGINAL MODEL

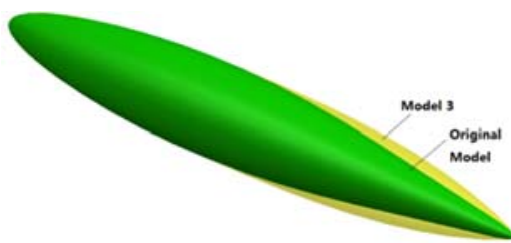

FIGURE VI. COMPARISON OF THE SUBMERSIBLE BETWEEN MODEL 3 AND THE ORIGINAL MODEL IN NX

\section{CONCLUSION}

This article provides a method for the rapid parametric modeling of SWATH by using the secondary development tool of NX, UG/OPEN API, in external mode. The parametric model of the underwater part of SWATH is established by using the parametric expression of the submersible and pillar of SWATH, which is written in NX. By changing the parameters of SWATH and using the secondary development program, the parameter file is generated, and then the new corresponding three-dimensional SWATH shipform is generated by inputting the parameter file in the background and modifying the expression in NX. This method greatly reduces the modeling process, improves the variability of the model. The model has a strong reusability and can be used for the subsequent design and optimization. It has a certain practical value in engineering.

\section{ACKNOWLEDGMENT}

This work was supported by the National Natural Science Foundation of China (Grant No. 51609036).

\section{REFERENCES}

[1] Vemengo, G., S. Brizzolara and D. Bruzzone, Resistance and Seakeeping Optimization of a Fast Multihull Passenger Ferry. International Journal of Offshore and Polar Engineering, 2015. 25(1): p. 26-34.

[2] Huang Dingliang, Xiao Shui line catamaran performance principle. 1993, Beijing: National Defense Industry Press.

[3] WANG Chao et al., Parametric modeling method for small waterplane droner based on uniform rational B-spline. Ship Science and Technology, 2017 (23): 143-148.

[4] Cheng C., et al., Study on Design Method of Small Waterplane Crossover Lines. China Shipbuilding, 2005 (02): p. 6-16.

[5] Beena, V.I. and V.A. Subramanian, Parametric studies on seaworthiness of SWATH ships. OCEAN ENGINEERING, 2003. 30(9): p. 1077-1106.

[6] Brizzolara, S., Parametric Optimization of SWAT-Hull Forms by a Viscous-Inviscid Free Surface Method Driven by a Differential Evolution Algorithm, in 25th Symposium on Naval Hydrodynamics. 2004: Canada.

[7] Brizzolara, S., The second generation of autonomous surface vessels: Optimized performance for AUVs assistance at Sea, in OCEANS 2015, IEEE. p. 1 - 8.

[8] Tang Ying, Wang Zhijian and Yang Kai, Parametric Modeling and Implementation of Marine Propellers Based on Secondary Development of UG. Ship Engineering, 2010 (04): pp. 52-55.

[9] Mei Xiaoning and Yang Shuxing, Parametric Modeling Based on Secondary Development of UG in Optimization Design. Science and Technology Review, 2010 (03): 29-32.

[10] LU Cong-hong, LIN Yan and JI Zhuo-shan, Three-dimensional Parameterization in Ship Design. 2007, Beijing: National Defense Industry Press.

[11] Gertler, M., Resistance Experiments on a Systematic Series of Streamlined Body of Revolution for Applications to the Design of High Speed. 1950, DTMB report C-297. 